\title{
El proyecto de vida de los jóvenes hijos de emigrantes retornados
}

\author{
Gerardo Hernández Rodríguez ${ }^{1}$ \\ Carmen María Martínez Conde ${ }^{2}$ \\ 1. Universidade da Coruña \\ gerardo@udc.es \\ 2. Universidad de Navarra \\ cmconde@alumni.unav.es
}

Recibido: 30-03-2008

Aceptado: 04-07-2008

\section{Resumen}

En este trabajo, se analiza la experiencia de los adolescentes nacidos en el extranjero de familias españolas, y más concretamente gallegas, emigrantes y que han llegado a España por sí mismos o con el retorno de sus progenitores, poniendo especial atención en su incorporación a la sociedad española, el contraste entre los sistemas de valores de nuestra sociedad y los suyos de procedencia, así como la asimilación, en su caso, de los valores y los hábitos familiares, dependiendo de que procedan de países iberoamericanos o europeos. Podemos destacar el idioma como signo de identidad y dividir las diferencias culturales en dos grandes grupos: los que encuentran una vida más segura, mejores infraestructuras, más abierta, pero menos humana, y los que perciben que hay más permisividad pero menos diferencias entre el país acogedor y el de origen. El primero proviene de países iberoamericanos y el segundo procede de países europeos.

Palabras clave: adolescencia; familia; identidad; retorno.

Abstract. The returned migrant children life project

In this work there is analyzed the experience of teenagers born abroad from Spanish families, and more concretely Galicians, emigrants and that have come to Spain on their own or with the return of his families, putting special attention on his incorporation to the Spanish society, the contrast with the values systems of our society and theirs of origin and assimilation, in his case, of the values and family habits, depending on they come from Latin-American or European countries. We can emphasize the language as a sign of identity an divide the cultural differences in two big groups; those who find a safer life, better infrastructures, more opened, but less human and that who perceives that there are more permissiveness but fewer differences between the host country and the country of origin. The first one come from Latin-American countries and the second come from European countries.

Key words: adolescence; family; identity; return. 


\author{
Sumario \\ Introducción Resultados, coincidencias y diferencias \\ Marco teórico e hipótesis Conclusiones \\ Los hijos de los retornados. Referencias bibliográficas \\ El caso de Galicia
}

\title{
Introducción
}

Uno de los fenómenos derivados de los intensos procesos migratorios que experimentó España durante el período 1951-1975 es la migración de retorno. A lo largo de la década de 1970, primeramente desde Europa y posteriormente desde las regiones inmigratorias tradicionales de España, se fueron consolidando diferentes flujos de retorno, que tienen su raíz en las diferentes crisis económicas que salpican la segunda mitad de los años setenta. Este es un período en el que, en áreas tradicionalmente emigratorias, los flujos humanos se invierten y, como consecuencia, comienzan a registrar un saldo migratorio positivo con el resto de España y respecto a la ya para entonces consolidada inmigración de españoles que regresan de sus destinos en Europa. En la ya amplia literatura generada por el tema de las migraciones de retorno, como hace Durand (2004: 103-116) al proponer una tipología de los migrantes de retorno y formular un nuevo enfoque y una nueva categoría analítica que permita entender y explicar el fenómeno, apenas ha tenido cabida el análisis de las experiencias de los más jóvenes miembros de las familias y, en especial, su experiencia educativa y la relación de ésta con la construcción de su identidad y su proyecto de vida, si exceptuamos a Verde Diego (2006: 69-90), que ha investigado el retorno de la segunda generación, referida concretamente al caso de Galicia.

Este trabajo, basado en una submuestra de las entrevistas realizadas en el marco del proyecto Identidades en construcción: Estudio de los procesos de adaptación de los adolescentes de familias inmigrantes (Plan Nacional I+D, SEJ200402006), analiza la experiencia vital y educativa de adolescentes nacidos en el extranjero de familias españolas emigrantes y que han venido a España por sí mismos o con el retorno de sus familias, poniendo especial atención en las diferencias reales o percibidas de estos adolescentes, dependiendo de que procedan de países iberoamericanos o europeos.

La submuestra a la que aquí se hace referencia corresponde a treinta y dos elementos, adolescentes, hijos de emigrantes gallegos retornados y que forman parte de la muestra establecida para el proyecto de investigación más arriba mencionado y compuesta por adolescentes de entre quince y diecinueve años de diversas procedencias, inmigrantes o hijos de inmigrantes en España con los que se realizaron sendas entrevistas en profundidad.

Desde el punto de vista técnico, la encuesta llevada a cabo para esta investigación con este subgrupo es de carácter estratégico, lo cual quiere decir que su fundamento muestral reside, principalmente, en el conocimiento del terre- 
no con que cuenta el investigador. El criterio clave de selección de las unidades del muestreo consiste en lo que ha venido en llamarse heterogeneidad ilustrada. El procedimiento muestral no es probabilístico y se asemeja al muestreo por cuotas. No cabe hablar, propiamente, de errores muestrales, dado que el azar en sentido estricto no interviene. La validez de los resultados, sin embargo, no queda por eso anulada; y depende, sobre todo, de la documentación existente sobre el universo muestreado (registros estadísticos de carácter censal o de otro tipo) y de la observación directa de la realidad con la que cuenta el investigador.

La edad de llegada al país receptor, las motivaciones existentes para el desplazamiento y el nivel de instrucción son factores importantes para la integración y la adaptación sociocultural, pero probablemente el nivel educativo es el factor principal, pues, de acuerdo con lo señalado por Richmond (1984: 551-568), la aculturación mínima indispensable para las interacciones en el nuevo contexto se diferencia de aquellos elementos posteriores de adaptación voluntaria.

La construcción de la identidad, en el caso del colectivo estudiado por nosotros, presenta unas particularidades muy concretas. Por un lado, los que han nacido en países iberoamericanos han tenido la misma lengua y prácticamente la misma cultura en la familia, en la escuela y en la sociedad, que vienen prácticamente a coincidir con la que se encuentran al llegar a España. Y, por otra parte, los que han nacido en países europeos no latinos, han tenido la misma lengua y cultura con la que se encuentran al venir a España en la familia y en los colegios o institutos españoles, en los que un buen número de ellos ha estudiado, pero no así en la sociedad correspondiente. Esta circunstancia va a hacer que estos jóvenes vivan su incorporación a la cultura y a la sociedad de sus padres y, en su caso, de sus abuelos, ya sean paternos, maternos o ambos de manera diferente.

El concepto de identidad, en este sentido, hace referencia, conforme a las acepciones tomadas del Diccionario de la Lengua Española (RAE: 2001: 843), al «conjunto de rasgos propios de un individuo o de una colectividad que los caracteriza frente a los demás y la conciencia que una persona tiene de ser ella misma y distinta de las demás». Pero, en sentido sociológico, también podemos entenderlo como «forma de autorreconocimiento de un grupo étnico o de un colectivo basado principalmente en una lengua, un territorio ocupado o reivindicado, un sistema de valores y creencias, un modo de vida, un conjunto de tradiciones y en ocasiones una reconstrucción histórica o legendaria del pasado" (Giner Abati, 2004: 699).

\section{Marco teórico e hipótesis}

Los adolescentes, en mayor medida quizás que otros grupos de edad, viven su vida cotidiana con varios grupos de referencia y, por tanto, están rodeados de muchos roles e individuos que deben integrar para construir su propia identidad. Los jóvenes de este estudio se encuentran con esta situación, agravada 
por el hecho de ser recibidos por una nueva cultura o quizás por una nueva forma de vida que deben integrar para formar su identidad.

El hijo del migrante se halla ante dos modelos culturales cuya reconciliación a veces no puede lograr: afectivamente, no puede romper con su modelo cultural de origen y tampoco le es permitido identificarse con la nueva cultura. Este hecho le afecta de modo determinante en la construcción de su identidad y, por tanto, en sus relaciones familiares, escolares o sociales.

Muchos de estos adolescentes hijos de familias migrantes acusan importantes diferencias formativas y culturales, se mueven dentro de un marco caracterizado por su proceso de socialización en el entorno que acogió a sus padres y en el que ellos nacieron (escuela, barrio, etc.), por modelos adquiridos de la red migrante familiar (cultura, religión, etc.) y por la influencia de la comunicación mediática propia de la cultura receptora, que, en estos casos, es la de origen de sus propios padres o, al menos, de alguno de ellos.

La hipótesis planteada estriba en que las peculiaridades de las expectativas y demandas de los adolescentes objeto de nuestro estudio constituyen una nueva dimensión de las diversidades culturales existentes entre las culturas de procedencia y las receptoras y sus impactos en las familias con elementos de diferentes generaciones. Frecuentemente, si la primera generación trata de mantener su cultura de origen, la segunda está más integrada en la de acogida, pero más inadaptada socialmente. En otro caso se producen conflictos intergeneracionales en el seno de la familia y en las relaciones sociales.

\section{Los hijos de los retornados. El caso de Galicia}

Los hijos de los gallegos que emigraron y que ahora han retornado constituyen un grupo con unas características particulares y que, por determinadas razones, merece, a nuestro entender, una referencia específica. Y estas razones son, fundamentalmente, que se trata de jóvenes hijos o nietos de españoles que, en la mayoría de los casos, han nacido y vivido su infancia e, incluso, su primera juventud en el continente americano, aunque también hay un número significativo que han venido al mundo en países centroeuropeos o en Gran Bretaña. Es más, se da ya el caso de que entre los que llegan procedentes de Iberoamérica los hay que son nietos de antiguos emigrantes españoles, mientras que los procedentes de países europeos son hijos de quienes emigraron en la segunda mitad del siglo XX. La muestra de individuos está formada por hijos de emigrantes gallegos retornados, con edades comprendidas entre los quince y los diecinueve años; el territorio de análisis es Galicia, que es la comunidad autónoma donde más incidencia ha tenido la emigración exterior.

Un aspecto común a todos los entrevistados, con respecto a la construcción de la identidad, es el hecho universal de que la familia desempeña un rol decisivo en la formación de la identidad y en la comunicación. Por ello, las formas de educación y socialización se han mantenido casi invariables; podríamos decir, en este sentido, que se ha cambiado de escenario, pero no de actores. 
Al tratar con adolescentes, somos conscientes de que las identidades, y no sólo por el hecho de construirse en relación con un proceso de retorno, están en un proceso de doble construcción. Por un lado, están en el camino de la búsqueda y de la definición de su propia identidad como ser humano - aspecto clave de la adolescencia-, mientras que, por otro, se trata de buscar su identidad en un nuevo país, en una nueva sociedad. Sin duda, el papel de las familias es fundamental, puesto que se trata del pilar sobre el que se apoya el adolescente.

Muchos de estos jóvenes viven un auténtico proceso de construcción o reconstrucción de su identidad, un proceso abierto e inconcluso, porque, en unos casos, cuando su procedencia lo es de países europeos desarrollados, perciben en su entorno una valoración más positiva que cuando proceden de países en vías de desarrollo o que han tenido que abandonar debido a crisis o decadencias económicas.

En el primero de estos supuestos, se encuentran a gusto en su parte de identidad vinculada a ese país o cultura y, de forma permanente u ocasional, presumen de ello. En el otro caso, si se percibe en el entorno una actitud de infravaloración, se instalan en su origen como un mecanismo de autodefensa frente a lo que consideran una agresión exterior o reniegan abiertamente de él, atribuyendo a un hecho meramente fortuito o circunstancial su nacimiento en aquel país. En uno u otro caso, según la perspectiva, se utiliza en uno u otro sentido el dicho de «se es de donde se nace y no de donde se pace» o viceversa.

No parece que ninguno de los entrevistados haya dejado a la familia «de lado" por el hecho de llegar a un país nuevo, ni siquiera, como ya hemos visto, parece que el retorno de sus padres haya sido el germen de problemas y discusiones. En la mayoría de los casos estudiados, los adolescentes encontraron ayuda en la familia. Unos porque supuso para ellos una guía del mundo en el que se adentraban, otros porque "siempre encuentran en ella el apoyo que necesitan».

El apoyo de la familia extensa ${ }^{1}$ es evidente para muchos de estos adolescentes cuando ésta se encuentra en el país al que llegan. Les tranquiliza la idea de tener primos en Galicia, y que incluso muchos les presenten a amigos o les enseñen la ciudad en la que van a vivir. Cuando se da el caso de que se deja a esta familia en el retorno, no se pierden los vínculos ni tampoco se pierde el apego hacia ella, de hecho, los adolescentes cuentan con medios rápidos y eficaces de comunicación. Esta familiaridad que tienen los jóvenes con los nuevos medios de comunicación permite que se mantengan lazos e importantes sentimientos de pertenencia.

Las crisis económicas vividas en los países receptores son causas que precipitan el retorno. Y así se ha puesto de manifiesto en naciones como Argentina y Suiza, país este último que se presenta en el año 2006 como origen principal del retorno. De Suiza regresaron 2.363 emigrantes gallegos, más que desde

1. Nos referimos a la familia que va más allá de la que se considera nuclear — formada por padres e hijos- L La familia extensa comprendería a abuelos, tíos, primos y demás ramas de parentesco. 
Venezuela, Argentina, Alemania, Reino Unido y Francia juntas, de donde lo hicieron un total de 2.346 emigrantes. El país helvético aporta ya el 37\% del total del retorno gallego.

Es preciso destacar también que una buena parte de los gallegos retornados, sobre todo los de las generaciones más jóvenes, no fijan su residencia en las aldeas o poblaciones que sus padres o abuelos dejaron décadas atrás, sino en comunidades de economía más pujante, como Madrid o Cataluña. Los gallegos venidos de Iberoamérica suelen ser profesionales o universitarios que buscan nuevas expectativas profesionales, mientras que, entre los que proceden de Europa, predominan las personas en edad de jubilación.

Las motivaciones para el regreso de los padres y, por consiguiente, de su llegada a España, son básicamente de dos tipos: familiar y económico. En el primer caso, las causas son evidentes, en el segundo, se ha podido comprobar como algunas de las expectativas profesionales de los padres no se han visto enteramente satisfechas o bien algunas ilusiones se truncaron. En gran parte de los casos que se han analizado, las familias llegaron con sus hijos pequeños, lo cual también supuso para los padres una "aventura», ya que, de alguna manera, ellos también tendrían que empezar de nuevo.

Podemos dividir la forma de llegada de los entrevistados en dos estados según su edad. El primero de ellos se refiere a su venida a Galicia cuando todavía eran pequeños, que son los que menos diferencias dicen haber encontrado entre dos culturas; el segundo se refiere a los que llegan en las edades del tiempo adolescente.

En los casos en que los entrevistados llegan cuando todavía tenían edades tempranas, suele haber un hecho significativo en común. Se trata de que los padres se plantean regresar en un momento en el que los hijos son todavía pequeños, y por ello regresan a Galicia antes de que se acostumbren a un país ajeno a la cultura familiar. El de un chico hijo de gallegos nacido en Suiza y que vino a España con ocho años es uno de los discursos que ejemplifican esta tendencia:

Más que nada por el miedo, debe ser, de, al crecer los chavales allí, que después no quieran venir para aquí.

Se vienen con los hijos pequeños o los mandan a España, porque, cuando son más mayores, no se quieren venir. De hecho, hay constancia de casos en que los hermanos mayores han tomado la decisión de quedarse en el país en que se encontraban y no venir con sus padres y hermanos menores a España.

En algunos casos, se toma la decisión de regresar por el hecho de llevar una vida más tranquila. Quienes responden así, vienen de países de América del Sur. Concretamente, un adolescente procedente de Argentina, donde había vivido los dieciséis primeros años de su vida, manifestaba:

Además, más que nada, yo creo que fue porque allá había [...] no tanto por lo económico, sino por la violencia que había y los robos [...] Se hacía difícil vivir allá. Entonces, pudiendo vivir acá, decidieron venir acá. 
Sin embargo, dentro del discurso del mismo entrevistado, analizamos la siguiente respuesta también acerca del porqué del regreso:

Un poco porque mi padre trabajaba en una multinacional de Estados Unidos y la multinacional cerró, pero volvió a abrir y le ofrecieron un trabajo, pero no lo quiso. No sé si fue por el estrés y esas cosas..., pero..., le ofrecieron una oportunidad acá y quiso venir.

En este caso, el regreso de este adolescente se veía marcado por la crisis del país en el que nació. El factor económico está también presente, a este respecto, en una adolescente de origen uruguayo:

Me vine porque..., por dinero, porque axá no daba. No alcanzaba para vivir mejor.

Otra de las respuestas acerca de la motivación del regreso se refiere a que con él se puede producir un aumento del nivel de vida. Podemos ejemplificarlo con el caso de un chico, nacido en Gran Bretaña, que llegó a Galicia cuando era pequeño:

Después de que naciera yo, ellos [sus padres] seguían trabajando en el hotel y a los dos años, después de que yo naciera, cuando yo tenía dos años, pues se plantearon la historia de si quedarse o de si volver a España, porque el resto de la familia ya había vuelto toda y mi padre pues le planteó a mi madre el hecho de volverse.

Cuentan también las experiencias de otros familiares que ya habían tomado la decisión de regresar, con lo cual se unen dos motivaciones: la de mejorar en el trabajo y, consecuentemente, en el nivel de vida, así como el éxito que otros familiares tuvieron después de regresar.

Motivación interesante lo es también el hecho de mejorar la vida del hogar. Va unida al retorno de la familia en su totalidad. Este tipo de regreso suele estar presente en aquellas personas que afirman que siempre quisieron volver y que vieron su marcha de Galicia como un abandono reversible:

Mi familia siempre quiso venir, era una meta que tenía... Eran emigrantes, pero siempre quisieron ser emigrantes retornados..., otra vez aquí [...] No fue una cosa de un día para otro, "nos vamos», no... Llevó su proceso de maduración, de preparar, de decir «bueno, a lo mejor tenemos que cambiar de país, hay que volver...".

Quien así se manifiesta es una joven de diecinueve años, hija de gallega y asturiano y nacida en Suiza.

Los que pensaron que la partida de Galicia sería para siempre, y sin embargo regresan, suelen hacerlo por un motivo imprevisto. En el siguiente caso, 
aparece el testimonio de una chica cuya familia regresó por un accidente laboral del cabeza de familia, procedente también del país helvético:

Si no fuera porque mi padre se lesionó allá y le dieron una paga para venirse..., no nos íbamos a venir, porque, una vez que te acostumbras allá, vienes de vacaciones y punto.

Y también se han encontrado casos en los que los adolescentes vienen a España con uno de sus padres, como consecuencia de una ruptura familiar. En los dos casos en los que se daba esta circunstancia, se trataba de las madres, y ambos procedían de América del Sur.

\section{Resultados, coincidencias y diferencias}

Cuando la procedencia de los padres es gallega para ambos, los hijos muestran una mejor adaptación y una serie de rasgos más arraigados, como es el uso del gallego. En este sentido, habría que recordar, como ya se ha observado, que «la mayor planificación del retorno en el caso de los emigrantes procedentes de Europa hace que, a su vuelta, se integren con más facilidad en la sociedad gallega, en tanto que las dificultades son mayores en el caso de los procedentes de América Latina, sobre todo de aquellos más jóvenes, nacidos muchas veces en los países de destino, que sufren mayor choque cultural, no sintiéndose de ninguna parte» (Hernández Borge, 2003: 159).

Los adolescentes, hijos de emigrantes retornados, suelen coincidir al hablar de sus madres - en el caso de que éstas no sean gallegas - como mujeres que añoran la vida que dejaron, mientras que, por el contrario, no encontramos esto cuando se trata de hablar de sus padres. Una hija de madre venezolana afirma:

Hay que reconocer que sí, que añora la vida de allí, porque claro, allí también vivió sus años de juventud, entonces sí que la añora.

Cuando el padre no es gallego, los hijos suelen mostrar que se les rechaza más por el hecho de ser extranjeros, aunque sean hispanoamericanos. El testimonio de un chico, hijo de colombiano y española, así lo pone de manifiesto:

Hombre, noto que mi padre pues aquí no está muy contento. Por eso que aquí se nota que hay mucha discriminación por..., por ser de allá, que lo tratan mal que o sea que es verdad que con él pudo haber injusticias con él por haber nacido allá.

Suele existir una coincidencia entre que los padres sean los dos gallegos y que el país de procedencia, por ello de retorno, sea de países europeos. De manera un tanto significativa, son los padres de procedencia gallega los que intentan, con más intensidad, que la emigración no haga olvidar a sus hijos de donde son. Además, al emigrar estos padres, el contacto con la tierra y su gente no se había cortado definitivamente, sino que se mantenía, porque siempre se pensaba en volver (Álvarez Silvar, 1997). 
Las familias de los adolescentes entrevistados vienen con el fin de instalarse definitivamente en Galicia. Retornan los que se pueden integrar laboralmente sin mayores problemas o instalar un negocio. Los que se dedicaban a trabajos relacionados con la hostelería vieron aumentadas sus expectativas. Es el caso de un adolescente, hijo de gallego e inglesa, procedente de Birmingham. Sus padres estaban más contentos con su trabajo y el nivel de vida aumentó:

Mi padre trabajó en Gran Bretaña como taxista, estuvo unos años como taxista y a mediados de los ochenta compró un bar [...] y fueron ampliándolo hasta hoy.

En el caso de los que vienen de Suiza, su discurso suele ser, tomando las palabras de una adolescente, el siguiente:

Aquí tampoco quiero decir que vivan mal. Es diferente. Hay otras cosas que allí no hay. Ni satisfechos ni preocupados, es diferente.

Por lo general, los que regresan a Galicia procedentes de países europeos suelen mostrar un ritmo semejante en cuanto a trabajo se refiere. Sin embargo, en cuanto al nivel de vida, suelen encontrar peor la situación de Galicia respecto del país del cual regresan. La siguiente reflexión lo pone de manifiesto:

Mis padres comparan bastante Suiza con aquí, porque, por ejemplo, lo que te decía antes, eso de los médicos porque igual uno está mal y dice: «Bueno, pues hacemos la revisión dentro de un año», y dicen: «Pues en Suiza habría... Ya está bien a los dos días». Y es lo que comparan, no comparan mucho más tampoco. No echan de menos ir allá.

Suelen quejarse del sistema administrativo y sanitario y afirman que esos dos aspectos funcionan peor que en el lugar del que regresan.

En algunos casos, se entiende que el nivel de vida es peor y que los padres llegaron a arrepentirse de la decisión de retornar. Así lo expresa un hijo de padres gallegos nacido en Suiza:

Mi madre tiene dicho varias veces que se había arrepentido de venirse para aquí. Era muy distinto a aquí, sobre todo en lo que ganaban cada mes.

Los procedentes de los países de América del Sur suelen afirmar que su calidad de vida aumenta en cuanto a seguridad. Además, son los que manifiestan que reciben un trato diferente, en ocasiones más negativo, como consecuencia del retorno:

Ellos se han acostumbrado a un ritmo de vida de allí [Venezuela], y al llegar aquí fue completamente distinto. Parecía que ellos, aunque han retornado a su país, parecían extranjeros, no eran bien acogidos aquí en España..., tanto en el trabajo como en muchas otras cosas. 
Las consecuencias positivas del retorno se centran, sobre todo, en la mejora familiar. Los siguientes testimonios son los de dos adolescentes hijos de emigrantes retornados de Gran Bretaña y Argentina, respectivamente.

Yo creo que tenemos aquí un nivel de vida mucho mejor que allí. Allí mis padres trabajaban horas y horas al día los dos en la tienda, ahora trabajan según les cuadra... No trabajan tantas horas. Nos vemos mucho más, porque yo a mi padre no lo veía prácticamente, las relaciones mejoraron bastante. Y bueno, es otra vida, allí los ingleses tampoco tienen la costumbre de las fiestas, no salir a pasear, y eso aquí sí que lo hay.

Mis padres me dicen que hay más oportunidades acá para mí y para mi hermano, no tanto para ellos. O sea, yo creo que sí. Lo único por lo que no están tan bien como querrían es porque tienen a mi hermano allá, entonces extrañan de él..., pero yo creo que mejoró bastante.

Los que provienen de países europeos suelen dejar familia nacida en aquellos países, o bien se trata de adolescentes que vienen solos a Galicia con el fin de estudiar y dejan tanto a su familia nuclear como a su familia extensa. El discurso sobre la familia suele ser más favorable en estos países; los adolescentes hijos de emigrantes retornados de los países comunitarios suelen coincidir con el discurso de una adolescente que considera lo siguiente:

La verdad es que, en España, la situación mejoró bastante, pero aún así sigue habiendo pequeñas diferencias, porque yo sigo teniendo familiares en Suiza, mis tíos y mis primos, y allí tienen una vida quizás un poco... Un nivel más alto en el sentido económico.

Los canales clásicos de comunicación son los que se utilizan con más frecuencia con la familia de origen. En ese discurso también vemos como la comunicación se restringe a ciertos acontecimientos familiares. Suele ser común, entre los adolescentes que estudiamos, el hecho de que hablan con la familia de origen sólo en fechas señaladas. Este hecho se ha observado más frecuentemente entre los procedentes de Iberoamérica, concretamente de Argentina y Colombia.

Sí, con mi familia más por teléfono porque son tíos y esas cosas y..., bueno, con mi hermano sí, por Internet y por teléfono... Pero con mi familia también, más que nada por teléfono... Cuando es un cumpleaños o algo así.

Sí, nos llamamos por teléfono, e-mails, Internet, en los cumpleaños siempre..., en los cumpleaños, Navidades, cualquier otro tipo de celebración como el día del amigo, que aquí no se celebra.

El uso de los medios de comunicación se ve influido, además, por el hecho de que los canales de comunicación no son accesibles para todo el mundo. De 
hecho, en algunos testimonios se ha podido analizar como muchas veces la comunicación se ralentiza y se espacia, por el hecho de que la familia de origen no cuenta con los canales de comunicación necesarios para contactar con la familia que llega a Galicia:

Ahora mismo es que lo del mail, no. Los chats estos pueden llegar... Lo que pasa es que..., a mi aquí sí, yo aquí en casa tengo Internet. Lo que pasa allí en Colombia un ordenador es un tesoro. No es como aquí, aquí todo el mundo tienen un ordenador funcionando, que si el otro..., tengo ya el viejo tirado. Allí en Colombia lo... Bueno, un ordenador viejo de aquí es una maravilla tenerlo. El único ordenador que hay está en un bar del pueblo y bueno, es como aquí, si quieres usar el ordenador, tienes que pagar, buf, te cobran bastante dinero y lo que es el..., la Internet, pues como que allí no funcionan muy bien $p o$ que las líneas no es que sean muy modernas por decirlo de alguna forma, tienen problemas para conectarte normalmente, cada dos por tres se les estropea la conexión.

Por lo que se refiere al empleo de uno u otro idioma, el reconocimiento más frecuente suele ser que, en familia, se habla más de uno, sobre todo cuando los padres son de orígenes distintos y se encuentran en países en los que no se habla español. Se suelen conservar y usar todos los idiomas, aunque el que habla la madre suele ser el que más se usa en casa. Muchos adolescentes son claros a la hora de describir estas ideas:

Mi madre nos obliga a que hablemos en inglés.

Hombre, en casa, pues, hay cierto bilingüismo. Nos comunicamos en inglés y español. Mis padres entre ellos hablan inglés, yo con mi madre y ella conmigo, bueno, y con mi hermano, hablamos en inglés, yo con mi padre hablo en español. Hay ahí un bilingüismo claro y luego también se habla más al tener familia materna.

A pesar que el aprendizaje del idioma en la familia es fundamental, algunas veces el idioma no sólo se aprende en ella. Los que más suelen coincidir en esto son los hijos de emigrantes hacia países europeos, que suelen aprender el idioma del país en colegios u otros centros:

Yo fui allá [en Suiza] a clases de español de..., lo que era el Consulado que son diez años y entre eso sí, nos dan historia, escribimos y sí que ayuda mucho. gallegos:

En Suiza..., cuando estábamos en Suiza, aprendí gallego porque me lo enseñaron mis padres, castellano porque lo veía en la televisión española, que allí la había, y aparte iba a clases de español, y después, en el colegio normal, francés. 
La mezcla de idiomas hace que no se olvide la situación de partida, los orígenes de la familia. De esta manera, el idioma es un símbolo claro de identidad y cultura, que además hay que conservar:

Básicamente, siempre he estado en contacto con esas tres lenguas y en mi casa en Suiza siempre se hablaba gallego, únicamente se hablaba francés cuando había otra persona que no entendiera eso, pero si no, siempre en gallego... Aparte de que había bastantes ámbitos en los que podías hablar gallego, porque o te juntabas con tu familia o, como decía antes, en los bares o sitios donde se reúne gente del mismo sitio.

Los hijos de emigrantes retornados que proceden de países de América del Sur manifiestan que usan palabras procedentes de otros países:

Mis padres hablan una cosa rara [risas] porque tienen palabras que siguen diciendo como en Argentina.

La cuestión del idioma, por lo general, no suele presentar problemas, ya que los procedentes de otros países europeos, además de haber aprendido la lengua del país de acogida, han aprendido el español en colegios españoles o en el seno de sus familias y, generalmente, lo hablan sin acento. Por su parte, los que proceden de Iberoamérica llegan habiendo hablado toda su vida en español, aunque con los giros y peculiaridades propias de los países de residencia anterior, y resultan más fácilmente identificables entre sus compañeros y amistades por el acento y por esos giros.

En su incorporación al sistema educativo español en general y al gallego en particular, lamentan haber perdido el uso de las lenguas propias de sus países de nacimiento, tales como el francés, el italiano, el alemán o el portugués, aunque los que nacieron en Gran Bretaña siguen usando el inglés, incluso en familia. Por otro lado, varios de estos adolescentes acusan problemas con el gallego en la escuela. Se incorporan a los estudios pasada la infancia y no entienden las clases que se imparten en esta lengua. No siempre llegan a comprender o a admitir por qué, si hay un idioma común en España, que es, además, el que ellos han aprendido en el país del que proceden, les tienen que imponer otra lengua local al tiempo que pierden la propia de aquel país que, además, tiene un rango nacional e, incluso, internacional. Los más mayores, aparte de costarles más el cambio de residencia, son los que acusan mayores problemas de integración escolar.

Algunos de estos problemas tienen que ver con el hecho de que ha habido profesores que han hecho chanzas, delante del resto del alumnado, a costa del acento de estos adolescentes o de las palabras o expresiones empleadas por los mismos, propias de su país de procedencia.

Una cuestión importante a tener en cuenta en este proceso socioeducativo es la de la identidad, que, muy frecuentemente, depende de la apreciación que en cada sociedad se haga de la condición de estos adolescentes. Se desta- 
ca que, con independencia de qué se consideren ellos, incluso los que dicen considerarse sólo gallegos o más españoles que otra cosa, siempre han sido allí considerados e identificados como españoles, gallegos, hijos de españoles o hijos de gallegos, mientras que aquí, frecuentemente, son considerados o tratados como «la inglesa», «los argentinos» $\mathrm{o}$ "el colombiano». Es como sentirse un poco extranjero en los dos sitios.

En Ginebra, donde vivía, pues hay tanta mezcla de nacionalidad que no se puede, que no se no..., no sentí en ningún momento discriminación.

Las costumbres no es algo que me haya chocado. Claro, aunque mi padre es argentino, mi madre es gallega... En ese sentido no... Te puedo decir que tienen costumbres muy parecidas y eso.

No sé, en general, yo te podría decir que son diferentes, pero tienen muchas cosas en común también... Yo, estando en Argentina, iba a un club de gallegos y a mi, escuchar a la gente hablar en gallego, no me es nada extraño ni mucho menos.

Por lo que se refiere a las comparaciones entre los sistemas educativos, aprecian un mejor sistema escolar en Gran Bretaña y en los otros países europeos, en tanto que los procedentes de países iberoamericanos estiman mejor el sistema español, aunque, por lo general, manifiestan que el trato allí, para con el profesorado, es más respetuoso que en España.

Asimismo, los procedentes de Iberoamérica hacen una valoración más positiva de los recursos y de las infraestructuras escolares españolas y destacan que, como promedio, el profesorado español es más joven que el de aquellos países.

Sin embargo, también hay quienes, procedentes de Costa Rica y de Ecuador, consideran que allí exigen más que en España, insistiendo en el mayor respeto al profesorado y matizando que en España hay muchos alumnos que van al colegio a hacer el gamberro y a perder el tiempo, mientras que en su país de origen, al no ser obligatoria la enseñanza, el que va a la escuela es porque realmente le interesa aprender.

Algunos adolescentes se quejan de que en el país iberoamericano del que proceden (Argentina) no les corregían las faltas de ortografía o no les enseñaban a acentuar las palabras conforme procede gramaticalmente, sino que lo hacían conforme a la pronunciación de su peculiar acento.

También en algunos casos hay diferencias en cuanto a la organización y el horario. En Brasil, el horario en los colegios es únicamente de mañana. En las entrevistas, acusan menor nivel y profundidad en las enseñanzas y más violencia, particularmente en los colegios estatales.

En el caso de Colombia, lo manifestado es que sólo van al colegio los hijos de los ricos. Los colegios, los institutos y la universidad ofrecen niveles y calidades inferiores a los de España y la gente que puede se va a estudiar fuera del país. 
Una diferencia señalada por un adolescente procedente de Colombia, y que él considera negativa para el caso de España, es que aquí, para desempeñar actividades profesionales vinculadas a los oficios, haya que estudiar teorías y no sólo enseñanzas prácticas específicas del oficio que se pretende desempeñar. Se trata de alguien que no muestra entusiasmo por los estudios y que dice que prefiere trabajar a estudiar, aprender las habilidades en un taller en lugar de cursar primero graduado escolar y después formación profesional.

La socialización que se produce con el cambio de residencia y, en ocasiones, de culturas, supone un factor muy importante en la experiencia educativa de estos adolescentes.

Tal y como ya ha quedado señalado, la adaptación de los jóvenes resulta más fácil cuando el retorno de los padres tiene lugar mientras los hijos todavía cuentan pocos años. En realidad, son frecuentes los casos de hermanos mayores que se han quedado en el país en el que han nacido o de hermanos menores que aun permanecen en los países de emigración con sus padres y que muestran serias reticencias a la hora de plantearse la venida a España.

En general, los adolescentes suelen encontrar diferencias culturales. Se trata de un caso diferente al de sus propios padres, los cuales marcharon de su lugar de origen siendo ya adultos y poseedores de una cultura de referencia con la que se podían identificar, cosa que resulta más difícil cuando se trata de menores traídos mientras aún eran pequeños o habiendo nacido en la migración. Entre los adolescentes entrevistados, los que más dificultades mostraron, en cuanto a la adaptación a los cambios, se encontraban los que procedían de países de América del Sur.

Muchos adolescentes decían en las entrevistas que, en los países de nacimiento, se juntaban con otras personas de su mismo ambiente cultural, que era similar al que iban a encontrarse en Galicia. Con ello, la construcción de la identidad estaba claramente marcada por la situación de partida. Veamos como ejemplo lo manifestado por una estudiante procedente de Suiza:

Básicamente, allí seguíamos nuestra cultura..., o sea, porque, aparte, era un sitio donde había muchos gallegos emigrantes y de nuestra zona había mucha gente, entonces ya había bares donde se juntaba gente de esos sitios, en los que todo el mundo se conocía.

Para mantener esa experiencia identitaria de «sentirse a sí mismo», el emigrante precisa mantener viva la referencia de sus orígenes. El cambio cultural no es radical, ya que son muchas las tradiciones que se guardan. Además, el hecho de vivir entre dos culturas es una situación de riqueza y privilegio, pero también de dualidad. El desarrollo en la identidad puede presentarse como una tarea compleja para los adolescentes y, en nuestro caso, más complicada para los descendientes del retorno.

Es constatable, pues, la tendencia a aprovechar y utilizar, de las diferentes sociedades, lo que consideran mejor de cada una, como pueden ser tradiciones o costumbres. Por eso, costumbres y tradiciones son otros de los elementos 
que consideramos básicos en la construcción de la identidad. A la vista de lo manifestado por los adolescentes hijos de emigrantes retornados, siguen manteniéndolas y no lo hacen como imposición. Sin embargo, no conservan tradiciones al estilo de sus padres, por el hecho de que muchas de ellas no se las plantean como algo necesario. En este sentido, nos estamos refiriendo a asociaciones de gallegos emigrantes, puesto que los adolescentes no suelen continuar con este tipo de agrupaciones.

A pesar de ello, también constan casos de adolescentes que se vieron obligados a deshacerse de algunas de sus costumbres y adaptarse a determinados horarios o, en su caso, abandonar registros lingüísticos.

Otro tanto ocurre con ciertas tradiciones o celebraciones. Nunca se ha dejado de celebrar la Navidad, independientemente de la firmeza de las creencias religiosas, del agnosticismo o, incluso, del ateísmo declarado de sus protagonistas. Sin embargo, salvo en algún caso de fidelidad absoluta a los Reyes Magos, todos los demás han ido incorporando a Papá Noel y conservándolo a su regreso a España. Este hecho se da principalmente en casos en que el padre es gallego y la madre, del país en el que los adolescentes han nacido, como es el ejemplo de un chico cuya madre es inglesa:

Ha sido muy característico en Navidad, pues, por ejemplo, el día de Reyes no lo celebramos, celebramos la Nochebuena y la Navidad. A nosotros, los regalos, pues, nos los trae Papá Nöel y no los Reyes.

Cuando los dos padres son gallegos, se mantiene «más viva» la tradición gallega. En este caso, no hay disparidades y la educación es bastante similar a la que dejaron sus padres cuando emigraron. En los siguientes testimonios, vemos reflejadas dichas ideas:

Lo que es la religión, siempre fuimos educados... Yo, por ejemplo, siempre fui a la iglesia allá [en Suiza] y mi hermano también parte del Catecismo.

Las costumbres, básicamente, se guardan las mismas que tienen todos los gallegos.

Mantenemos poco la festividad; sí, muy poco, porque mis padres son de aquí y es diferente. Pero mi padre sigue viviendo en Suiza... Mi madre es ahora emigrante retornada, pero mi padre sigue viviendo... Lleva ya treinta años en Suiza, sigues teniendo ese vínculo.

En los países de emigración, conservaban costumbres y tradiciones españolas y, en España, conservan costumbres y tradiciones de aquellos lugares, como es, por ejemplo, en familias que han vivido en Iberoamérica, la "celebración de los 15», es decir, la fiesta que se les ofrece a las niñas el día que cumplen los quince años de edad y que es una especie de rito de paso a la adolescencia o, lo que sería en España, en otros tiempos, la "puesta de largo». 
También resulta significativo el uso de la gastronomía. En los países de emigración, se acostumbraba a utilizar muy frecuentemente la cocina española en general y la gallega en particular, mientras que, al regresar a España, también frecuentemente se acude a la cocina propia de los países en los que se vivió, o a conservar ciertas costumbres como tomar te, los que estuvieron en Gran Bretaña, o mate los que vivieron en Argentina, llegando incluso a buscar productos típicos de allí y que es difícil encontrar en los comercios españoles. Este hecho es celebrado por los jóvenes, que mantienen así vivo el recuerdo de los sabores de los lugares en los que nacieron y en los que transcurrió su infancia. Ante la pregunta de si se seguían manteniendo las tradiciones, un adolescente respondía:

Tanto como tradición, no, pero a lo mejor el tipo de alimentación sí, sí que se cuida mucho lo que comíamos allí. Pues no sé, no sabría decirte qué comida, pero sí que hay detalles en casa que dices: «Como lo hacíamos allá». (Nacida en Suiza e hija de asturiano y gallega)

Tomar mate, eso sí que es una tradición... [...] Pero después tradición, tradición... No, porque toda la vida mi madre vivió haciendo lo que hacía su madre en Galicia. Mi padre no, pero tenía abuelos gallegos, así que siempre fue como llevar una vida medio gallega en Argentina.

En cuanto a determinadas circunstancias y comportamientos sociales, los procedentes de países tales como Suiza, aprecian mayor orden y seguridad allí que en España, mientras que quienes proceden de Iberoamérica hacen una valoración radicalmente opuesta, resaltando la inseguridad ciudadana y los riesgos de asaltos y otros delitos existentes en aquellos países. Y, por lo que se refiere al carácter, se manifiestan de idéntica forma. Para quienes proceden de Gran Bretaña y países centroeuropeos, el carácter y el trato en España es más abierto y amable, en tanto que quienes han nacido y vivido en Iberoamérica, la percepción es a la inversa, contraponiendo un carácter, por ellos percibido, más serio e incluso adusto en los españoles y concretamente en Galicia, frente a un carácter más abierto, festivo y animado de los iberoamericanos. Incluso llegan a compararse con los andaluces en España. Dicen que allí la gente es más alegre, más risueña, más campechana, y que aquí está como enfadada e incluso es más arisca, cerrada, criticona y fiscalizadora de las vidas ajenas.

\section{Conclusiones}

Las conclusiones se derivan de los propios resultados de la investigación y se han ido exponiendo a lo largo de este trabajo. En cualquier caso, la percepción de su identidad, su adaptación a la sociedad y a la cultura de sus mayores $y$, por descontado, su voluntad de permanecer en la misma o de regresar a aquella en la que nacieron, en relación con su proyecto de vida, es destacable 
también el hecho de que la práctica totalidad tiene entre sus proyectos de futuro quedarse a vivir en España, regresar a sus países de nacimiento sólo en vacaciones o para visitar a sus parientes, así como por razones de trabajo, en el caso de que allí tuvieran más posibilidades que en España.

Los entrevistados son conscientes de vivir entre dos culturas. Esa situación puede verse desde una doble óptica. En primer lugar, se ubican los que viven esa situación como una ventaja; en este grupo, están los que hablan varias lenguas - la del país de nacimiento, gallego y español—, los que son hijos de padres gallegos y los que no encuentran grandes diferencias en cuanto a costumbres se refiere. En segundo lugar, están los que viven la situación con dificultad; a él pertenecen aquellos que tienen dificultades con la lengua, son generalmente chicos, y encuentran un ambiente más arisco.

Las dificultades para la adaptación se originan, en determinados supuestos, no por exclusión o marginación social, sino por añoranza del lugar del que se procede, por las amistades que allí se dejaron e, incluso, por la idealización de un país en el que han nacido pero que no conocen y en el que vivieron poco tiempo al trasladarse a España con una corta edad, en función de las cosas que les han contado sus padres.

Es menester también dejar constancia de que la toma de la decisión del regreso, asumida en familia, ha sido propiciada preferentemente por la figura materna. Es, básicamente, una decisión meditada, ya que son diversos los factores que se ponen en la balanza.

La descripción de la percepción de la situación familiar es manifestada, en la mayor parte de los casos, como algo muy satisfactorio. En el sentido más personal, los adolescentes analizaron su autopercepción identitaria y cultural con continuas referencias a la familia, de lo que se deriva que lo que sucede al grupo afecta al individuo.

En la llegada de las familias, siempre se da una readaptación — que, en vista de los resultados, ni es motivo de crisis, ni cambia la configuración de los proyectos familiares-, hay también una novedad y, a pesar de las dificultades que puedan aparecer, se da un enriquecimiento cultural. Pero también se pone de manifiesto la añoranza por lo que se deja, o bien por lo distinto que está todo cuando se regresa. En el caso de los adolescentes, su apego se da por lo primero; sin embargo, al no tener una vida larga y consolidada, en general se adaptan de manera positiva.

Procede, asimismo, destacar los casos en los que se pone de manifiesto la influencia de nuevos sistemas de valores. En este sentido, los procesos de integración influyen para variar ciertos patrones.

Una característica significativa, en relación con el hecho del retorno, es que los gallegos están más dispuestos a volver que los ciudadanos procedentes de otros territorios. En una visión muy general, puede tenerse en consideración que muchos de ellos dejaron familia cuando emigraron. Además, gran parte de los matrimonios de los padres de los adolescentes objeto de nuestro estudio están formados por padre y madre gallegos, con lo que la idea del apego a la tierra estaría más enraizada y, por consiguiente, las expectativas del regreso. 
La idea del apego es digna de ser tenida en cuenta, sobre todo si la asociamos a grupos de edad. Muchas de las tradiciones de los padres han sido abandonadas por los hijos. Destaca el hecho de que no son continuadores de las asociaciones surgidas con la emigración. El que retorna, que se podría decir que emigra de nuevo, parece que no se desvincula del todo del país que le acogió. Además, como padres, los emigrantes tienen una doble influencia para socializar a sus hijos: la del país de acogida y la del país que en un pasado dejaron, que, en definitiva, y como se ha podido deducir de los resultados de este trabajo, son factores importantes, junto con el proceso educativo y el sistema de socialización, a la hora de configurar el proyecto de vida futura de estos adolescentes.

\section{Referencias bibliográficas}

Álvarez SiLVAR, G. (1997). La migración de retorno en Galicia. Santiago de Compostela: Xunta de Galicia.

Díez NiCOLÁs, J. (1998). Actitudes hacia los inmigrantes. Madrid: Ministerio de Trabajo y Asuntos Sociales-IMSERSO.

- (1999). Los españoles y la inmigración. Madrid: Ministerio de Trabajo y Asuntos Sociales-IMSERSO.

DuRAND, J. (2004). «Ensayo teórico sobre la migración de retorno. El principio del rendimiento decreciente». Cuadernos Geográficos de la Universidad de Granada, $35,103-116$.

Giner Abati, F. (2004). «Identidad». En: Uña Juárez, O. y Hernández SÁnChez, A. Diccionario de Sociología. Madrid: ESIC.

Hernández Borge, J. (2003). «La inmigración exterior en Galicia». Papeles de Geografia, 37, 155-164.

HERNÁNDEZ RodríGUEZ, G. (2005). «La diversidad cultural y los procesos de adaptación de los adolescentes de familias inmigrantes». Libro de actas. VI Conferencia Iberoamericana sobre la Familia. Las Familias y las Culturas. La Habana (Cuba).

Pino Juste, M. R. y Verde Diego, G. (2006). «Emigración de retorno. Análisis de la situación a través de historias de vida». Migraciones, 20. Madrid: Instituto Universitario de Estudios sobre Migraciones. Universidad Pontificia Comillas, 201-230.

Real Academia Española (2001). Diccionario de la Lengua Española. XXII Edición. Madrid.

RichmOND, A. H. (1984). «Adaptation et conflicts socio-culturels dans les pays d'inmigration». Revue Internationale des Sciences Sociales, XXXVI (3), 551-568. UNESCO.

TERRÉN LALANA, E. (2002). «La etnicidad y sus formas: aproximación a un modelo complejo de la pertenencia étnica». Papers, 66. Barcelona: Universitat Autònoma de Barcelona.

Verde Diego, C. (2006). «Migración de retorno en Galicia: Aspectos psicosociais e emocionais da segunda xeración». Revista Galega de Ciencias Sociais, 5, 69-90.

Veredas Muñoz, S. (1999). «Procesos de construcción de identidad entre la población inmigrante». Papers, 57. Barcelona: Universitat Autònoma de Barcelona. 